\title{
Coronavirus Disease 2019: Knowledge, Attitude, Practice, and Perceived Barriers among Health care Workers at Cairo University Children Hospital, Egypt
}

\author{
Yasmine S. Galal ${ }^{1}$, Walaa A. Abuelhamd ${ }^{2 *}$, Tamer A. Abdel Hamid ${ }^{2}$, Nema R. Elsayed ${ }^{3}$ \\ ${ }^{1}$ Department of Public Health and Community, Faculty of Medicine, Cairo University, Giza, Egypt; ${ }^{2}$ Department of Pediatrics, Faculty \\ of Medicine, Cairo University, Giza, Egypt; ${ }^{3}$ Department of Pediatric Nursing, Faculty of Nursing, MUST University, Giza, Egypt
}

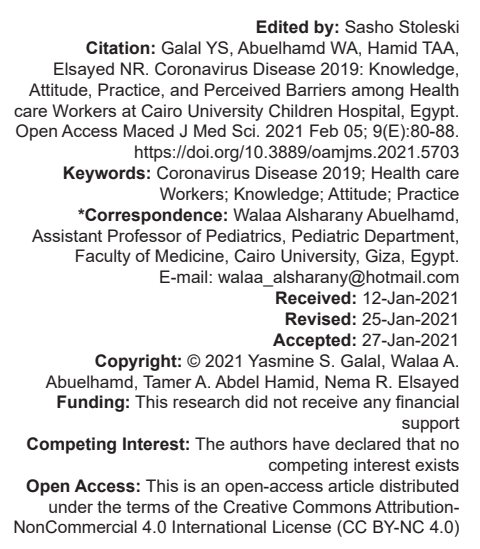

\section{Introduction}

Coronavirus disease 2019 (COVID-19) is an emerging respiratory disease caused by a novel human coronavirus severe acute respiratory syndrome coronavirus 2 (SARS-COV-2) and was first reported in Wuhan, China, in December 2019 [1]. Due to the rapid spread and sustained transmission of the disease to many countries, the World Health Organization (WHO) has declared COVID-19 as a public health emergency on January 30, 2020, and as a pandemic on March 12, 2020 [2].

Globally, COVID-19 pandemic resulted in $18,354,342$ confirmed cases and 696,147 deaths on August 05, 2020, as per the WHO reports [3]. In Egypt, the first confirmed COVID-19 case was reported on February 14, 2020, which was the first reported case in Africa [4], and by August 2020, there were 94,752 confirmed cases and 4912 deaths. On March 19, the Egyptian government has took various actions to slow down the spread of COVID-19 including, closing all restaurants, cafes, and public places form $7 \mathrm{pm}$ till 6 am [5], allocating extra human and financial resources needed to contain the outbreak, increasing the number of peripheral laboratories that can test for SARSCOV-2, increasing testing capacity, and applying strong disease surveillance and contact-tracing efforts [6].

Infection with COVID-19 virus can range from being asymptomatic to a one causing severe illness. According to the Center for Disease Control and Prevention, about $80 \%$ of infected cases have mild or no symptoms, while about $20 \%$ develop severe complications including acute respiratory distress syndrome, sepsis, septic shock, organ failure, and death in about $2 \%$ of cases [7]. To date, there is no antiviral therapy or vaccine to prevent infection with SARS-COV-2, and thus, implementation of preventive measures is crucial especially among health care workers (HCWs) and patients' close contacts [8].

Frontline HCWs who are primarily involved in hospitalizing COVID-19 patients are exposed to serious occupational risks including frequent exposure to infection, psychological stress, fatigue, occupational stigma, and physical violence [9]. On July 1, 2020, the number of infections among doctors with COVID-19 virus exceeded 3000, while the number of deaths 
has reached 108 representing about $5-7 \%$ death rate among medical staff according to the Egyptian Medical Syndicate [10].

Transmission of COVID-19 among all groups of HCWs whether frontline or non-frontline is facilitated by overcrowding, lack of isolation facilities, insanitary environment, and probably by insufficient knowledge and misunderstandings about infection control practices among HCWs which, in turn, result in delayed diagnosis and spread of the disease [11], [12]. Understanding HCWs' knowledge, attitude, and practices (KAPs) help identifying the knowledge gaps related to the disease and planning effective strategies for behavioral change [13]. Hence, this study was conducted to investigate KAPs regarding COVID-19 disease among $\mathrm{HCW}$ in Cairo University Children Hospital (CUCH).

\section{Methods}

\section{Study design, period, and setting}

This cross-sectional study was conducted in $\mathrm{CUCH}$ over 6 months duration from the beginning of June 2020 till the end of November 2020.

\section{Study population and sampling}

A convenient sample of 537 non-frontline HCWs (doctors and nurses) working at $\mathrm{CUCH}$ was recruited for the study.

\section{Non-frontline HCWs}

Are those who are not directly involved in COVID-19 prevention and control and not having direct contact with confirmed or suspected cases through patients' screening, testing, nursing specimen collection, and treatment.

\section{Study tools and data collection technique}

Because of the lockdown in Egypt at the time of conduction of the study and to apply social distancing, data collection was done online through a Google Forms and the participants were invited to complete and submit it through a link sent through WhatsApp. For HCWs who could not use the Google Forms, questionnaires were also printed and distributed by data collectors. Two hundred and seven questionnaires were completed as Google Forms, while 330 were collected as printed selfadministered questionnaires. The questionnaire used was designed to cover the following information:

1. Sociodemographic data and job characteristics including qualification and years of experience
2. Sources of knowledge about COVID-19 disease, data related to previous infection of HCWs with COVID-19 virus, diagnostic measures, and consequent actions. Sources of knowledge about COVID-19 were inquired using multiple options format

3. Knowledge of the study participants regarding coronavirus disease 2019: A total of 23 questions addressed the incubation period and modes of transmission, susceptibility, symptoms and complications, and factors that could reduce the risk of transmission, prevention, and treatment of the disease. The questions were formatted in closed-ended format with answers in the form of either: Yes, no, do not know, or multiple-choice options. Correct answers scored 1, while false and do not know scored 0 . Questions used in this section were adopted from the available literature [12], [13], [14]

4. Participants' attitudes related to COVID-19 disease; 13 questions were used to assess: Participants' willingness to increase their knowledge about the disease and to inform friends and relatives about it, their interest in the following COVID-19 disease updates in the Egyptian community, readiness to follow the infection control measures produced by the WHO and to accept being isolated if infected, their fear of being infected at work, and readiness to report infection to the hospital director and to get vaccinated if the vaccine became available in the market (all scored as 1 for agree and 0 for not sure or disagree)

5. Practices of HCWS related to COVID-19 disease; eight questions assessed participants behaviors as follows: Avoiding touching eyes, mouth, and nose as much as possible, washing hands frequently with soap and water for $20 \mathrm{~s}$ at least, wearing personal protective equipment (PPE) when dealing with patients, correct putting on and taking off of PPE, wearing the mask when going out, avoiding crowded places as much as possible, and avoiding shaking hands since the pandemic started (all scored as 1 for yes and 0 for sometimes and no). Questions used in this section were adopted from the available literature [12], [13], [14]

6. Barriers to applying infection control measures in hospitals: Closed-ended questions with multiple option format (yes, no, and not sure) were used to assess participants' perception toward the possible barriers. These questions were adopted from the available literature [13].

The original language of the questionnaire was English; they were translated to Arabic by two experts followed by back translation to English by other independent experts. 


\section{Pilot testing}

The preliminary data collection form was tested on $54 \mathrm{HCWs}(10 \%$ of the sample size) who were later excluded from the analysis, to assess the clarity and comprehension of questions, and the time needed to answer the questionnaire. The internal consistency of the study questionnaire was assessed by calculating the Cronbach's alpha with reliability coefficient of 0.816 , 0.746 , and 0.712 for the KAP sections, respectively.

\section{Data management and statistical analysis}

Pre-coded revised data were entered into the Statistical Package for the Social Sciences (SPSS) version 21.0 (SPSS Inc. IBM, U.S.A.). For the knowledge (23 points), attitude (13 points), and practice (8 points): Correct responses assigned 1 point while do not know or incorrect responses received nil. For the knowledge scores, those attained $\geq 18$ points (out of 23 points, the $50^{\text {th }}$ percentile for the score) were assigned as being knowledgeable, while those who attained $<18$ points were assigned as being not knowledgeable. For the attitude scores, those attained $\geq 10$ points (out of 13 points, the $50^{\text {th }}$ percentile for the score) were assigned as having good attitude, while those who attained $<10$ points were assigned as having non-favorable attitude. For the practice scores, those attained $\geq 1$ points (out of 8 points, the $50^{\text {th }}$ percentile for the score) were assigned as having good practice, while those who attained $<1$ point were assigned as having faulty practice. These cutoffs were employed for the generation of logistic regression analysis to determine the possible predictors for good KAP. For categorical data, frequencies and percentages were used for reporting, Chi-square was used for comparison. For continuous data, mean, standard deviation, and median were used, independent t-test was used for comparison. Pearson rank correlation tests were used to find any correlation between KAP scores. $p$ $\leq 0.05$ was considered statistically significant.

\section{Ethical considerations}

The Ethical Review Committee at the Pediatric Department, Faculty of Medicine, Cairo University revised and approved the study protocol. Informed consent form was obtained after proper orientation regarding the study objectives, data confidentiality, as well the potential impact of the study on the health services. Participants were informed of their right to withdraw from the study at any stage.

\section{Results}

Out of a total of 591 questionnaires, 537 were fully completed and included in the analysis

sociodemographic characteristics and variables related to previous infection with coronavirus disease 2019 among the study participants are shown in Table 1. More than half $(53.6 \%)$ of the study participants were female, mean age was $29 \pm$ 7 years. About $60 \%$ of the respondents were nurses and $40 \%$ were doctors. Out of the 537 participants, $225(42 \%)$ had at least a bachelor's degree, $40 \%$ had a diploma or certificate, and a minority had a Ph.D $(5.6 \%)$. Nearly $61 \%$ of the study sample did not attend any training courses or lectures about COVID-19. About $15 \%$ of the study participants were infected with COVID-19 and the majority (93\%) reported being infected. The highest reporting frequency was to the Infection Control Committee (73.1\%) followed by the head of the unit and the hospital director (27\% each). The most common method of diagnosis was polymerase chain reaction (PCR) $(37.7 \%)$ and computed tomography (CT) chest $(25 \%)$, while the least were clinical diagnosis (13.1\%) and history of contact with a confirmed COVID-19 case (14.3\%). After reporting infection with COVID-19, $83.3 \%$ of infected cases were subjected to home isolation and supportive management, while $3.9 \%$ needed hospital isolation, and $12.8 \%$ needed further investigations by PCR, X-ray, and CT chest.

Table 1: Sociodemographic, previous infection with COVID-19 among HCWs at Cairo University Children Hospital

\begin{tabular}{|c|c|c|}
\hline $\begin{array}{l}\text { Socio-demographic characteristics and previous infection with } \\
\text { COVID-19 variables }\end{array}$ & $\begin{array}{l}\text { Number } \\
(\mathrm{n}=537)\end{array}$ & $\%(100)$ \\
\hline \multicolumn{3}{|l|}{ Age } \\
\hline$<30$ & 321 & 59.8 \\
\hline$\geq 30$ & 216 & 40.2 \\
\hline \multicolumn{3}{|l|}{ Gender } \\
\hline Male & 249 & 46.4 \\
\hline Female & 288 & 53.6 \\
\hline \multicolumn{3}{|l|}{ Job title } \\
\hline Doctor & 216 & 40.2 \\
\hline Nurse & 231 & 59.8 \\
\hline \multicolumn{3}{|l|}{ Qualification } \\
\hline Bachelors & 225 & 41.9 \\
\hline Masters & 72 & 13.4 \\
\hline Diploma & 54 & 10.1 \\
\hline $\mathrm{PhD}$ & 30 & 5.6 \\
\hline Certificate & 156 & 29.0 \\
\hline \multicolumn{3}{|l|}{ Years spent in current specialty } \\
\hline$<5$ & 318 & 59.2 \\
\hline $5-10$ & 147 & 27.4 \\
\hline$\geq 10$ & 72 & 13.4 \\
\hline \multicolumn{3}{|l|}{ Have you attended any training courses related to COVID-19? } \\
\hline Yes & 207 & 38.5 \\
\hline No & 330 & 61.5 \\
\hline \multicolumn{3}{|l|}{ Have you been infected with coronavirus? } \\
\hline Yes & 84 & 15.6 \\
\hline No & 453 & 84.4 \\
\hline \multicolumn{3}{|l|}{ How were you diagnosed? (not mutually exclusive, $n=84$ ) } \\
\hline Clinically & 11 & 13.1 \\
\hline CT chest & 21 & 25.0 \\
\hline Serology & 0 & 0.0 \\
\hline PCR & 30 & 35.7 \\
\hline All of the above & 0 & 0.0 \\
\hline Contact with a confirmed COVID-19 case & 12 & 14.3 \\
\hline \multicolumn{3}{|l|}{ Have you reported infection? $(n=84)$} \\
\hline Yes & 78 & 92.9 \\
\hline No & 6 & 7.1 \\
\hline \multicolumn{3}{|l|}{ Who did you report to? (not mutually exclusive, $n=78$ ) } \\
\hline Infection Control Committee 1 & 57 & 73.1 \\
\hline Head of the unit 2 & 21 & 26.9 \\
\hline Hospital director 3 & 21 & 26.9 \\
\hline One of my colleagues 4 & 18 & 23.1 \\
\hline \multicolumn{3}{|l|}{ Procedures done after reporting $(n=78)$} \\
\hline Home isolation and supportive management & 65 & 83.3 \\
\hline Further investigations, for example, PCR, $\mathrm{X}$-ray, and CT chest & 10 & 12.8 \\
\hline Hospitalization & 3 & 3.9 \\
\hline
\end{tabular}




\section{Knowledge about COVID-19 disease among HCWs}

The respondents were asked some questions (23) to assess their knowledge regarding COVID-19 disease including incubation period, modes of transmission, susceptibility, clinical symptoms, complications, prevention, and treatment (Table 2). Doctors were more knowledgeable than nurses regarding incubation period of the disease (56\% vs. $41 \%, p<0.001)$, most common clinical symptoms $(85 \%$ vs. $44 \%, p<0.001)$, and other less reported symptoms (96\% vs. $86 \%$, p < 0.001). More doctors than nurses correctly identified that HCWs are more likely to get infected with COVID-19 (100\% vs. 97\%, p = 0.046) and that children and young adults are not exempt from infection and need to take measures to prevent infection (96\% vs. 87\%, $p=0.001$ ). A significantly higher percent of doctors knew that there is currently no vaccine in the Egyptian market to prevent COVID-19 (97\% vs. $76 \%, p<0.001)$ and that influenza vaccine does not protect against the disease (76\% vs. $65 \%, p=0.001)$. More physicians than nurses correctly mentioned that the majority of COVID-19-infected cases is mild and can be treated at home (93\% vs. $72 \%, p<0.001)$ and that antibiotics are not the first line of treatment $(85 \%$ vs. $50 \%, p<0.001)$. Nurses were significantly more knowledgeable than doctors regarding 2 items only; they correctly knew that chemoprophylaxis with chloroquine is the most effective way for the prevention of COVID-19 in health-care settings (32\% vs. $19 \%, p<0.001)$ and that HCWs should have their temperature measured daily before entering the hospital ( $94 \%$ vs. $86 \%, p=0.003)$. The mean knowledge score of the study group was $18.0 \pm 2.0$ with a significantly higher knowledge score among physicians than nurses (19.22 \pm 1.43 vs. 17.16 $\pm 2.01, p<0.001)$. About $61 \%$ of the study group was considered knowledgeable (scored $\geq 18$ out of 23 points).

\section{Sources of knowledge about COVID-19} among HCWs

The most common sources of knowledge about coronavirus infection among the study group were television (44.1\%) followed by social media $(39.7 \%)$, international websites, for example, WHO $(28 \%)$, and senior colleagues $(20.1 \%)$, while the least was seminars and workshops (12.8\%) (Figure 1).

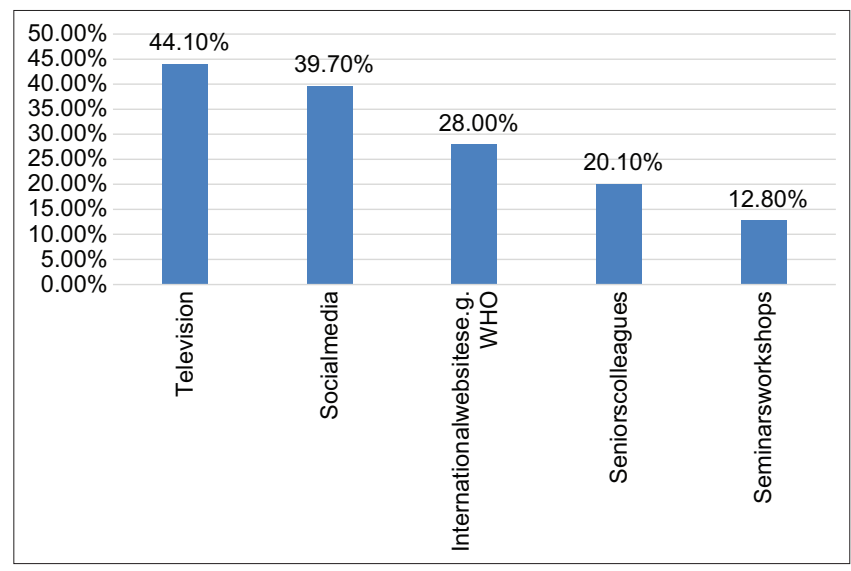

Figure 1: Sources of knowledge (\%) about coronavirus disease 2019 among health care workers in Cairo University Children Hospital

\section{disease \\ Attitudes of HCWs regarding COVID-19}

Attitudes of HCWs as regards coronavirus infection are presented in Table 3 . In most of the items (10 out of 13), nurses had significantly more positive attitude compared to doctors, where a significantly higher percent of nurses believed that one should follow the infection control measures produced by the WHO $(99 \%$ vs. $92 \%, p<0.001)$ as they believed these could protect to a great extent from being infected

Table 2: Comparison between doctors and nurses as regards knowledge related to COVID-19 (correct responses)

\begin{tabular}{|c|c|c|c|c|c|c|c|}
\hline \multirow[t]{3}{*}{ Knowledge of health care workers regarding COVID-19 } & \multicolumn{6}{|l|}{ Job title } & \multirow[t]{3}{*}{$p$-value ${ }^{*}$} \\
\hline & \multicolumn{2}{|l|}{ Doctors } & \multicolumn{2}{|l|}{ Nurses } & \multicolumn{2}{|l|}{ Total } & \\
\hline & $\mathrm{n}(216)$ & $\%(100)$ & $\mathrm{n}(321)$ & $\%(100)$ & $\mathrm{n}(537)$ & $\%(100)$ & \\
\hline What is the incubation period of COVID-19? (multiple options) & 120 & 56 & 132 & 41 & 252 & 47 & $<0.001^{*}$ \\
\hline \multicolumn{8}{|l|}{ Modes of transmission of COVID-19 include: } \\
\hline Inhalation of droplets resulting from direct contact with an infected person $(T)$ & 216 & 100 & 318 & 99 & 534 & 99 & $<0.001^{*}$ \\
\hline Contact with surfaces soiled with the virus $(T)$ & 201 & 93 & 306 & 95 & 507 & 94 & 0.277 \\
\hline Eating or contact with infected animals $(F)$ & 105 & 49 & 33 & 10 & 138 & 26 & $0.040^{*}$ \\
\hline Most common clinical symptoms of COVID-19 include all the following except (multiple options) & 183 & 85 & 141 & 44 & 324 & 60 & $<0.001^{*}$ \\
\hline Other reported symptoms of COVID-19 include (multiple options) & 207 & 96 & 276 & 86 & 483 & 90 & $<0.001^{*}$ \\
\hline COVID-19-infected individuals with no fever could not transmit infection to others $(F)$ & 177 & 82 & 231 & 72 & 408 & 76 & $0.013^{*}$ \\
\hline Health-care providers are more likely to get infected with COVID-19 (T) & 216 & 100 & 312 & 97 & 528 & 98 & $0.046^{*}$ \\
\hline $\begin{array}{l}\text { Elderly and people with chronic diseases are more susceptible to get severe disease if got infected with COVID-19 } \\
\text { (T) }\end{array}$ & 207 & 96 & 315 & 98 & 522 & 97 & 0.232 \\
\hline Children and young adults do not need to take measures to prevent infection with COVID-19 (F) & 207 & 96 & 279 & 87 & 486 & 91 & $0.001^{*}$ \\
\hline Complications of COVID-19 include (multiple options) & 216 & 100 & 315 & 98 & 531 & 99 & 0.130 \\
\hline Risk of transmission of COVID-19 could be reduced by (multiple options) & 216 & 100 & 315 & 98 & 531 & 99 & 0.086 \\
\hline When should hand hygiene be done? (multiple options) & 216 & 100 & 315 & 98 & 531 & 99 & 0.130 \\
\hline There is a vaccine in the Egyptian market for preventing COVID-19 (F) & 210 & 97 & 243 & 76 & 453 & 84 & $<0.001^{*}$ \\
\hline Influenza vaccine could protect from COVID-19 (F) & 165 & 76 & 210 & 65 & 375 & 70 & $0.001^{*}$ \\
\hline Antibiotics are the first line for the treatment of COVID-19 (F) & 183 & 85 & 159 & 50 & 342 & 64 & $<0.001^{*}$ \\
\hline The majority of COVID-19-infected cases is mild and can be treated at home $(T)$ & 201 & 93 & 231 & 72 & 432 & 80 & $<0.001^{*}$ \\
\hline Contacts of COVID-19 patients should be isolated in a proper place and placed under & 207 & 96 & 300 & 94 & 507 & 94 & 0.452 \\
\hline $\begin{array}{l}\text { It is recommended to isolate a patient with confirmed COVID-19 in an airborne infection isolation room with exhaust } \\
\text { (T) }\end{array}$ & 126 & 58 & 213 & 66 & 339 & 63 & 0.150 \\
\hline $\begin{array}{l}\text { Chemoprophylaxis with chloroquine is considered currently the most effective way for prevention of COVID-19 in } \\
\text { health-care settings }(\mathrm{T})\end{array}$ & 42 & 19 & 102 & 32 & 144 & 27 & $<0.001^{*}$ \\
\hline It is important that all HCWs have their temperature measured daily before entering the hospital $(T)$ & 186 & 86 & 303 & 94 & 489 & 91 & $0.003^{*}$ \\
\hline $\begin{array}{l}\text { HCWs in the triage area should be trained to spot symptoms of potential COVID-infection such as cough, fever, } \\
\text { and difficulty breathing }(T)\end{array}$ & 216 & 100 & 318 & 99 & 534 & 99 & 0.277 \\
\hline Preventing coronavirus disease 2019 at hospitals could be done by (multiple options) & 213 & 100 & 321 & 100 & 534 & 100 & \\
\hline
\end{tabular}


(100\% vs. $94 \%, p=0.002)$. More nurses than doctors expressed their willingness to be vaccinated against COVID-19 disease if the vaccine became available in the Egyptian market ( $87 \%$ vs. $83 \%, p=0.001$ ) and to be isolated in a suitable place if they got infected $(90 \%$ vs. $74 \%, p<0.001)$. A significantly higher percent of nurses believed that COVID-19 pandemic could be controlled in Egypt (46\% vs. 28\%, p < 0.001) and were keen of following the disease updates in the Egyptian community $(66 \%$ vs. $17 \%, p<0.001)$. The mean positive attitude score of the study group was $10.0 \pm$ 1.0 with a significantly higher positive attitude among nurses than physicians $(10.36 \pm 1.24$ vs. $9.29 \pm 1.54$, $p<0.001)$. About $64 \%$ of the study participants were considered as having a positive attitude (scored $\geq 10$ out of 13 points). A significant negative correlation was found between knowledge score and attitude score $(r=-0.167, p<0.001)$.

\section{disease \\ Practices of HCWs regarding COVID-19}

The majority of HCWs mentioned that they wash their hands frequently with soap and water for 20 $\mathrm{s}$ at least $(87 \%)$, avoid touching their eyes, mouth, and nose, as much as possible $(72 \%)$ and avoid shaking hands since the pandemic started $(65 \%)$, with a significantly higher good practice among doctors than nurses $(p<0.001)$. A significantly higher percent of nurses mentioned that they correctly put on and take off the PPE $(78 \%$ vs. $68 \%, p=0.049)$ (Table 4$)$. The mean practice score of the study group was $1.0 \pm 2.0$ with a significantly higher good practice among nurses than physicians $(1.57 \pm 1.66$ vs. $0.99 \pm 1.16, p<0.001)$. About $63 \%$ of the study participants were considered as having good practice (scored $\geq 1$ out of 8 points). A significant negative correlation was found between knowledge score and practice score $(r=-0.134$, $p=0.002)$.

\section{Predictors of good knowledge and positive attitude regarding COVID-19 among HCWs}

Age $<30$ years (odd ratio [OR] $=1.932,95 \%$ confidence intervals [Cl] 1.165-3.203, $p=0.011$ ), being a doctor $(\mathrm{OR}=13.822,95 \% \mathrm{Cl} 2.155-88.639, \mathrm{p}=$ $0.006)$, and higher qualification $(\mathrm{OR}=2.485,95 \% \mathrm{Cl}$ $1.354-4.561, p=0.003$ ) were the significant positive predictors of acquiring knowledge about COVID-19 among the study participants (Table 5). Receiving training courses about COVID-19 (OR $=2.083,95 \%$ $\mathrm{Cl} 1.353-3.205, \mathrm{p}=0.001$ ) were the sole significant negative predictor of acquiring knowledge about the disease. Age $<30$ years $(\mathrm{OR}=4.245,95 \% \mathrm{Cl} 2.715$ $6.636, p<0.001$ ) was the only significant predictors for positive attitude among the study group.

\section{Perceived barriers to applying infection control measures against coronavirus virus}

Respondents were asked about the barriers to applying infection control measures in health-care facilities against COVID-19 (Figure 2). The majority mentioned overcrowdings in health-care facilities $(78.2 \%)$ and insufficient infection control policies and procedures $(62.6 \%)$. More than half of the study sample stated lack of necessary information about the disease among HCWs (56.4\%) and deficient infection control supplies $(53.6 \%)$. Lack of training programs for $\mathrm{HCW}$ on a regular basis, non-compliance of HCWs

Table 3: Comparison between doctors and nurses as regards positive attitude related to COVID-19

\begin{tabular}{|c|c|c|c|c|c|c|c|}
\hline \multirow{3}{*}{ Attitude of health care workers regarding COVID-19 } & \multicolumn{6}{|l|}{ Job title } & \multirow{3}{*}{$p$-value ${ }^{*}$} \\
\hline & \multicolumn{2}{|l|}{ Doctors } & \multicolumn{2}{|l|}{ Nurses } & \multicolumn{2}{|l|}{ Total } & \\
\hline & $\mathrm{n}(216)$ & $\%(100)$ & $\mathrm{n}(321)$ & $\%(100)$ & $\mathrm{n}(537)$ & $\%(100)$ & \\
\hline I am willing to increase my knowledge about COVID-19 & 213 & 99 & 321 & 100 & 534 & 99 & 0.065 \\
\hline I agree that all HCWs should follow the infection control measures produced by the WHO for reducing risk of infection & 198 & 92 & 318 & 99 & 516 & 96 & $<0.001^{*}$ \\
\hline I believe that following infection control measures could protect to a great extent from infection & 216 & 100 & 303 & 94 & 519 & 97 & $0.002^{*}$ \\
\hline I think that involving HCWs in infection control programs in hospitals has a role in reducing the risk of infection & 210 & 97 & 318 & 99 & 528 & 98 & 0.167 \\
\hline I agree that patients with COVID-19 should be isolated & 198 & 92 & 315 & 98 & 513 & 96 & $0.001^{*}$ \\
\hline I believe that COVID-2019 pandemic could be controlled in Egypt & 60 & 28 & 147 & 46 & 207 & 39 & $<0.001^{*}$ \\
\hline I am not afraid of being infected with COVID-19 at work, and I believe I could defeat the virus & 60 & 28 & 180 & 56 & 240 & 45 & $<0.001^{*}$ \\
\hline I will inform the hospital director and all my contacts if I got infected with COVID-19 & 207 & 96 & 315 & 98 & 522 & 97 & 0.232 \\
\hline Willing to get vaccinated against COVID-19 if the vaccine became available & 180 & 83 & 279 & 87 & 459 & 86 & $0.001^{*}$ \\
\hline I believe that infection control measures should be applied with all patients not only infected cases & 66 & 31 & 240 & 75 & 306 & 57 & $<0.001^{*}$ \\
\hline I am keen of following COVID-19 updates in the Egyptian community & 36 & 17 & 213 & 66 & 249 & 46 & $<0.001^{*}$ \\
\hline I am willing to accept the idea of being isolated in a hospital/at home if I got infected with COVID-19 & 159 & 74 & 288 & 90 & 447 & 83 & $<0.001^{*}$ \\
\hline Planning to inform my relatives and friends about COVID-19 and how to reduce the risk of being infected & 180 & 83 & 279 & 87 & 459 & 86 & $0.006^{*}$ \\
\hline
\end{tabular}

Table 4: Comparison between practices of doctors and nurses regarding COVID-19

\begin{tabular}{|c|c|c|c|c|c|c|c|}
\hline \multirow[t]{3}{*}{ Practice } & \multicolumn{6}{|l|}{ Job title } & \multirow[t]{3}{*}{$\mathrm{p}$-value } \\
\hline & \multicolumn{2}{|l|}{ Doctors } & \multicolumn{2}{|l|}{ Nurses } & \multicolumn{2}{|l|}{ Total } & \\
\hline & $\mathrm{n}(216)$ & $\%(100)$ & $\mathrm{n}(321)$ & $\%(100)$ & $\mathrm{n}(537)$ & $\%(100)$ & \\
\hline I avoid touching my eyes, mouth, and nose, as much as possible & 171 & 79 & 213 & 66 & 384 & 72 & $0.001^{*}$ \\
\hline I wash my hands frequently with soap and water for $20 \mathrm{~s}$ at least or with a disinfectant & 192 & 89 & 276 & 86 & 468 & 87 & $<0.001^{*}$ \\
\hline I wear personal protective equipment when dealing with patients & 192 & 89 & 288 & 90 & 480 & 89 & 0.246 \\
\hline I wear the medical mask when going out & 177 & 82 & 270 & 84 & 447 & 83 & 0.243 \\
\hline I cover my nose and mouth during coughing and sneezing & 198 & 92 & 252 & 79 & 450 & 84 & $<0.001^{*}$ \\
\hline I try to avoid crowded pales as much as possible & 192 & 89 & 297 & 93 & 489 & 91 & 0.351 \\
\hline I can correctly put on and take off PPE to protect myself and others from the risk of transmission of coronavirus & 147 & 68 & 249 & 78 & 396 & 74 & $0.049^{*}$ \\
\hline I avoid shaking hands since the COVID-19 pandemic started & 177 & 82 & 174 & 54 & 351 & 65 & $<0.001^{*}$ \\
\hline
\end{tabular}


Table 5: Logistic regression model for predictors of good knowledge and positive attitude regarding COVID-19 among HCWs

\begin{tabular}{|c|c|c|c|c|c|c|c|c|c|c|}
\hline \multirow{3}{*}{$\begin{array}{l}\text { Practice of health care workers regarding } \\
\text { COVID-19 }\end{array}$} & \multicolumn{5}{|c|}{ Predictors of knowledge } & \multicolumn{5}{|c|}{ Predictors of attitude } \\
\hline & \multirow{2}{*}{ B coefficient } & \multirow[t]{2}{*}{$p$-value } & \multirow[t]{2}{*}{ OR } & \multicolumn{2}{|c|}{ 95\% C.I. for EXP (B) } & \multirow[t]{2}{*}{ B coefficient } & \multirow[t]{2}{*}{$p$-value ${ }^{*}$} & \multirow[t]{2}{*}{ OR } & \multicolumn{2}{|c|}{$95 \%$ C.I. for EXP (B) } \\
\hline & & & & Lower & Upper & & & & Lower & Upper \\
\hline Age $(<30)$ & 0.659 & 0.011 & 1.932 & 1.165 & 3.203 & 1.446 & $<0.001$ & 4.245 & 2.715 & 6.636 \\
\hline Gender (females) & -1.504 & $<0.001$ & 4.504 & 2.754 & 7.352 & -0.140 & 0.550 & 0.896 & 0.549 & 1.376 \\
\hline Title (doctors) & 2.626 & 0.006 & 13.822 & 2.155 & 88.639 & -21.471 & 0.999 & 0.000 & 0.000 & - \\
\hline Years of experience $(>10)$ & -0.233 & 0.508 & 0.792 & 0.397 & 1.579 & -1.076 & 0.003 & 2.932 & 1.451 & 5.917 \\
\hline Higher qualification & 0.910 & 0.003 & 2.485 & 1.354 & 4.561 & -0.181 & 0.666 & 0.835 & 0.368 & 1.893 \\
\hline Received training courses about COVID-19 & -0.734 & 0.001 & 2.083 & 1.353 & 3.205 & -0.066 & 0.756 & 0.936 & 0.618 & 1.418 \\
\hline Previous exposure to COVID-19 & -0.054 & 0.801 & 1.055 & 0.695 & 1.602 & -0.108 & 0.606 & 0.898 & 0.596 & 1.352 \\
\hline
\end{tabular}

COVID-19: Coronavirus disease 2019; HCWs: Health care workers; p-value: *Chi-square of independence; Cl: Confidence interval; OR: Odds ratio.

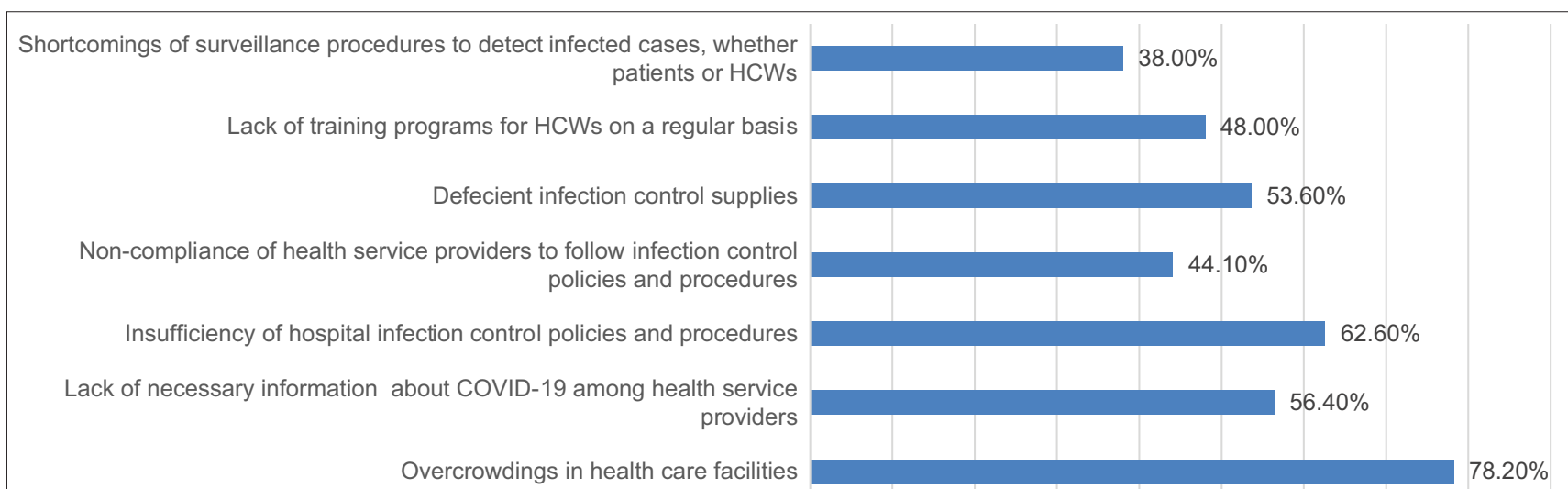

0.00\% $10.00 \% 20.00 \% 30.00 \%$ 40.00\% $50.00 \% 60.00 \% 70.00 \% 80.00 \% 90.00 \%$

Figure 2: Barriers to applying infection control measures against coronavirus disease 2019 in health-care settings as perceived by health care workers

to follow the infection control policies and procedures, and shortcomings of surveillance procedures to detect infected cases whether from patients or HCWs, were perceived as barriers for $48 \%, 44 \%$, and $38 \%$ of the study participants, respectively.

\section{Discussion}

COVID-19 is a rapidly expanding global health emergency affecting all groups of the population, especially HCWs. Sufficient knowledge about the disease among HCWs may positively affect their attitudes and practices which have a major impact in reducing further spread of the disease [15]. Hence, this study was conducted to assess the KAPs of HCWs towards COVID-19 disease in $\mathrm{CUCH}$.

In the current study, a good level of knowledge was detected among HCWs regarding COVID-19 as about $61 \%$ of the respondents were considered as having sufficient knowledge about the disease. However, a higher percent was detected in a study conducted in Uganda where $69 \%$ of the participants were deemed knowledgeable regarding coronavirus infection [14]. Moreover, in another study conducted in China, $89 \%$ of the HCWs surveyed showed sufficient knowledge of COVID-19 [16]. In contrast, poor level of knowledge about the disease symptoms and modes of transmission was detected in a study from the United
Arab Emirates [17]. These variations among studies could be attributed to many factors including different methodological techniques and tools, disparities in sources of knowledge and acquiring information, and lack of training/educational programs.

Irrespective of their job title (doctors/nurses), almost all participants $(99 \%)$ in this study correctly identified regular hand washing, social distancing, and using face masks as the main preventive measures for reducing spread of COVID-19. In accordance with our findings, adequate knowledge regarding the preventive measures of the disease was detected in an Indian study by Roy et al. [18]. However, Kumar et al. reported a moderate to poor level of knowledge related to using face masks for prevention COVID-19 [19]. In the current study, physicians were more knowledgeable regarding the majority of knowledge items (21 out of 23 questions); a possible explanation is that doctors are actively involved in seeking medical information for improving patient outcomes. In accordance with our study, Abdel Wahed et al. found a significantly higher knowledge level among physicians than nurses and pharmacists [20]. However, no significant differences in knowledge regarding COVID-19 were detected among HCWs in Uganda regardless of their profession or qualification [14].

In the present study, age $<30$ years and higher qualification of $\mathrm{HCW}$ sere the significant positive predictors of good knowledge regarding COVID-19. This may be explained by the higher tendency of younger generations with high education 
levels to gain information from a diversity of sources, especially the internet and social media which are less used by older ones. Similarly, several studies reported higher knowledge among younger age groups with higher levels of education [1], [21].

The most common sources of knowledge about COVID-19 in the current study were television and social media, while the least were seminars and workshops. Moreover, receiving educational programs about COVID-19 were surprisingly a negative predictor of acquiring knowledge about the disease. A possible explanation could be attributed to many factors including lack of time among HCWs and non-organized content of the programs which is not directed to the HCWs' needs. Moreover, at the beginning of the COVID-19 pandemic, there was a lot of contradictory information about the disease which could have negatively influenced the knowledge level of HCWs. This finding suggests the need for conducting well-organized and properly planned educational programs to different groups of HCWs according to their needs and work load.

The current study detected an overall positive attitude of HCWs toward COVID-19, 64\% of respondents were considered as having a positive attitude. More than half of the participants $(55 \%)$ mentioned that they were afraid of being infected with COVID-19 at work. However, higher percentages were reported by Zhong et al. and Maleki et al. where $83.1 \%$ and $89.2 \%$, of HCWs, respectively, were afraid and felt at risk of getting infected with coronavirus [1], [22].

Unexpectedly, there was a significant negative correlation between knowledge score and both attitude and practice scores in the present study. A possible explanation could be due to deficient infection control resources, which was perceived by $53.6 \%$ of HCWs as a barrier to applying infection control. In addition, attitude of HCWs may be negatively affected by their peers even if they have adequate knowledge. This finding was contradictory to other studies which reported that higher knowledge levels were associated with a more favorable attitude [16], [21]. In our study, nurses had a significantly higher positive attitude than doctors regarding COVID-19 despite their lower knowledge score. A possible explanation is that risk perception differs among HCWs and could strongly affect their mental health and, in turn, their perception toward the risk [23]. Nurses are usually exposed to a higher risk of acquiring infection than doctors due to their prolonged contact with patients which makes them more aware of the risk and consequently this affects their attitudes. A significantly higher percent of nurses believed that COVID-19 pandemic in Egypt could be controlled and expressed their interest in following the disease updates in the Egyptian community. Similar results were reported from a study conducted in Egypt to assess the KAPs of HCWs regarding COVID-19, despite the physicians' higher knowledge levels in that study, their attitude was less favorable as regards the
COVID-19 situation in Egypt and the capability of the government to control the disease [20]. Age $<30$ years was the sole significant positive predictor for positive attitude in the current study which could be explained by the malleability of younger generations to accept change in attitude.

In the current study, $63 \%$ of HCWs were assigned as having good practices toward COVID-19. Most of the study participants performed the main preventive practices against the disease including washing hands frequently with soap and water for $20 \mathrm{~s}$ at least $(87 \%)$, wearing face mask when going outdoors (83\%), and avoiding crowded places as much as possible (91\%). Nurses had an overall significantly higher mean practice score than doctors (1.57 \pm 1.66 vs. $0.99 \pm 1.163, p<0.001)$, however, no significant correlation was found between practice score and attitude score. One of the main causes of acquiring COVID-19 disease is the incorrect wearing and removal of PPE [24], in our study, a significantly higher percent of nurses than doctors stated that they can correctly put on and take off PPE (78\% vs. 68\%, $p=0.049)$.

The most frequently mentioned barriers for applying infection control measures in hospitals in the current study were as follows: Overcrowdings in health-care facilities $(78.2 \%)$, insufficient infection control policies and procedures $(62.6 \%)$, lack of necessary information about the disease among HCWs (56.4\%), and deficient infection control supplies (53.6\%). Non-compliance of HCWs to follow infection control measures was mentioned by $44 \%$ of the study participants. Similarly, Saqlin et al. found that overcrowding in emergency rooms was perceived by the majority of HCWs as a barrier to infection control, however, $31.6 \%$ and $36.7 \%$ of HCWs in that study thought that not wearing a mask and not doing hand washing were not barriers to infection control [13].

This study is one of the few studies [20] that assessed the KAPs of HCWs in Egypt regarding COVID-19. However, it has some limitations including assessment the KAPs of non-frontline $\mathrm{HCW}$ s in $\mathrm{CUCH}$, so the results may not be generalizable to all groups of HCWs. Using an online data collection method for a part of the study, sample may have resulted in recall bias.

\section{Conclusion}

In the current study, HCWs in general expressed good knowledge, positive attitude, and good practice toward COVID-19 despite some gaps that were detected in specific items. Surprisingly, nurses had a significantly higher positive attitude and good practice score than doctors. Thus, proper planning of educational programs that are directed according to the 
needs of different groups of HCWs is crucial. Improving HCWs' practices are necessary through continuous monitoring and evaluation. Knowledge of HCWs about COVID-19 was mainly derived from less genuine sources (television and social media) which could have affected their knowledge levels and ultimately attitude and practice as well, so it is recommended that the Ministry of Health should provide authentic and up-todate information targeting all HCWs. The main barriers for applying infection control measures in hospitals as perceived by $\mathrm{HCW}$ in the current study were overcrowding, insufficient infection control policies and procedures, and deficient infection control supplies. Therefore, effective policies should be established by the government and policy-makers to overcome the previously mentioned barriers.

\section{Acknowledgments}

The authors are thankful to the Chairman of the Pediatric Department at Cairo University Hospital for his kind permission to conduct the study. The authors are also thankful to all doctors and nurses who agreed to participate in this study.

\section{References}

1. Zhong BL, Luo W, Li HM, Zhang QQ, Liu XG, Li WT, et al. Knowledge, attitudes, and practices towards COVID-19 among Chinese residents during the rapid rise period of the COVID-19 outbreak: A quick online cross-sectional survey. Int J Biol Sci. 2020;16(10):1745-52. https://doi.org/10.7150/ijbs.45221

PMid:32226294

2. World Health Organization Director-General's Opening Remarks at the Media Briefing on COVID-19-11; 2020. Available from: https://www.who.int/director-general/speeches/detail/whodirector-general-s-opening-remarks-at-the-media-briefing-oncovid-19---11-march-2020. [Last accessed on 2020 Sep 05]. https://doi.org/10.1093/ww/9780199540884.013.u23682

3. World Health Organization. Coronavirus Disease (COVID-19). Situation Report 198. Available from: https://www.apps.who. int/iris/bitstream/handle/10665/333735/nCoVsitrep05Aug2020eng.pdf? sequence $=1 \&$ isAllowed $=y$. [Last accessed on 2020 Sep 05].

4. World Health Organization. Coronavirus Disease 2019 (COVID-19) Situation Report 26. Geneva: World Health Organization; 2020. Available from: https://www.who.int/docs/ default-source/coronaviruse/situation-reports/20200215-sitrep26-covid-19.pdf. [Last accessed on 2020 Sep 10].

5. Kasemy ZA, Bahbah WA, Zewain SK, Haggag MG, Alkalash SH, Zahran E, et al. Knowledge, attitude and practice towards COVID-19 among Egyptians. J Epidemiol Glob Health. 2020;10(4):378-85. https://doi.org/10.2991/jegh.k.200909.001 PMid:33009730

6. World Health Organization. WHO Delegation Concludes COVID- 19 Technical Mission to Egypt. Geneva: World Health
Organization; 2020. Available from: https://www.reliefweb.int/ report/egypt/who-delegation-concludes-covid-19-technicalmission-egypt. [Last accessed on 2020 Sep 10]. https://doi. org/10.1016/s0968-8080(02)00085-x

7. The Novel Coronavirus Pneumonia Emergency Response Epidemiology Team. The epidemiological characteristics of an outbreak of 2019 novel coronavirus diseases (COVID19) in China. Chin J Epidemiol. 2020;41:145-51. https://doi. org/10.46234/ccdcw2020.032

PMid:32064853

8. Bhagavathula AS, Aldhaleei WA, Rahmani J, Mahabadi MA, Bandari DK. Novel Coronavirus (COVID-19) Knowledge and Perceptions: A Survey on Healthcare Workers. MedRxiv; 2020. https://doi.org/10.1101/2020.03.09.20033381

9. World Health Organization. Coronavirus Disease (COVID-19) Outbreak: Rights, Roles and Responsibilities of Health Workers, Including Key Considerations for Occupational Safety and Health; 2020. Available from: https://www.who.int/publications/i/ item/coronavirus-disease-(covid-19)-outbreak-rights-roles-andresponsibilities-of-health-workers-including-key-considerationsfor-occupational-safety-and-health. [Last accessed on 2020 Sep 10]. https://doi.org/10.1055/s-0040-1716817

10. Egypt Today Staff. Coronavirus Death Toll among Doctors Rises to 108. Egypt Today; 2020. Available from: https:// www.egypttoday.com/Article/1/89157/ Coronavirus-death-tollamong-doctors-rises-to-108. [Last accessed on 2020 Sep 10].

11. Wu Z, McGoogan JM. Characteristics of and important lessons from the coronavirus disease 2019 (COVID-19) outbreak in China: Summary of a report of 72314 cases from the Chinese center for disease control and prevention. J Am Med Assoc. 2020;323(13):1239-42. https://doi.org/10.1001/jama.2020.2648 PMid:32091533

12. McEachan R, Taylor N, Harrison R, Lawton R, Gardner $P$, Conner M. Meta-analysis of the reasoned action approach (RAA) to understanding health behaviors. Ann Behav Med. 2016;50(4):592-612. https://doi.org/10.1007/ s12160-016-9798-4

PMid:27169555

13. Saqlain M, Munir MM, Rehman SU, Gulzar A, Naz S, Ahmed Z, et al. Knowledge, attitude, practice and perceived barriers among healthcare workers regarding COVID-19: A crosssectional survey from Pakistan. J Hosp Infect. 2020;105(3):41923. https://doi.org/10.1016/j.jhin.2020.05.007

PMid:32437822

14. Olum R, Chekwech G, Wekha G, Nassozi D, Bongomin F. Coronavirus disease-2019: Knowledge, attitude, and practices of health care workers at Makerere University Teaching hospitals, Uganda. Front Public Health. 2020;8:181. https://doi. org/10.3389/fpubh.2020.00181

PMid:32426320

15. Gan WH, Lim JW, Koh D. Preventing intra-hospital infection and transmission of COVID-19 in health care workers. Saf Health Work 2020;11:241-3. https://doi.org/10.1016/j. shaw.2020.03.001

PMid:32292622

16. Zhang $M$, Zhou M, Tang $F$, Wang $Y$, Nie $H$, Zhang L, et al. Knowledge, attitude, and practice regarding COVID-19 among healthcare workers in Henan, China. J Hosp Infect. 2020;105(2):183-7. https://doi.org/10.1016/j.jhin.2020.04.012 PMid:32278701

17. Bhagavathula AS, Aldhaleei WA, Rahmani J, Mahabadi MA, Bandari DK. Knowledge and perceptions of COVID-19 among health care workers: Cross-sectional study. JMIR Public Health Surveill. 2020;6(2):e19160. https://doi.org/10.2196/ preprints. 19160

PMid:32320381 
18. Roy D, Tripathy S, Kar SK, Sharma N, Verma SK, Kaushal V. Study of knowledge, attitude, anxiety and perceived mental healthcare need in Indian population during COVID-19 pandemic. Asian J Psychiatr. 2020;51:102083. https://doi. org/10.1016/j.ajp.2020.102083

PMid:32283510

19. Kumar J, Katto M, Siddiqui AA, Sahito B, Jamil M, Rasheed N, et al. Knowledge, attitude, and practices of healthcare workers regarding the use of face mask to limit the spread of the new coronavirus disease (COVID-19). Cureus. 2020;12(4):e7737. https://doi.org/10.7759/cureus.7737

PMid:32455057

20. Abdel Wahed WY, Hefzy EY, Ahmed MI, Hamed NS. Assessment of knowledge, attitudes, and perception of health care workers regarding COVID-19, a cross-sectional study from Egypt. J Community Health. 2020;45(6):1242-51. https://doi. org/10.1007/s10900-020-00882-0

PMid:32638199
21. Abdelhafiz AS, Mohammed Z, Ibrahim ME, Ziady HH, Alorabi M, Ayyad $\mathrm{M}$, et al. Knowledge, perceptions, and attitude of Egyptians towards the novel coronavirus disease (COVID-19). J Community Health. 2020;45:881-90. https://doi.org/10.1007/ s10900-020-00827-7

PMid:32318986

22. Maleki S, Najafi F, Farhadi K, Hosseini F, Naderi M. Knowledge, attitude and behavior of health care workers in the prevention of COVID-19. BMG Med Educ 2020. https://doi.org/10.21203/ rs.3.rs-23113/v1.

23. Yesilgul G, Cicek H, Avci M, Huseyniklioglu B. Nurses' knowledge levels and perceptions regarding occupational risks and hazards. Int J Caring Sci. 2018;11(2):1117-24. https://doi. org/10.21203/rs.3.rs-23113/v1

24. World Health Organization. Guidance for Health Workers. Geneva: World Health Organization; 2020. Available from: https:// www.who.int/emergencies/diseases/novelcoronavirus-2019/ technical-guidance/health-workers. [Last accessed on 2020 Sep 15]. https://doi.org/10.2471/blt.19.249417 